\title{
Trauma, post-traumatic stress disorder and psychiatric disorders in a middle-income setting: prevalence and comorbidity
}

Sarah Dorrington, Helena Zavos, Harriet Ball, Peter McGuffin, Fruhling Rijsdijk, Sisira Siribaddana, Athula Sumathipala and Matthew Hotopf

\section{Background}

Most studies of post-traumatic stress disorder (PTSD) in low- and middle-income countries (LMICS) have focused on 'high-risk' populations defined by exposure to trauma.

\begin{abstract}
Aims
To estimate the prevalence of post-traumatic stress disorder (PTSD) in a LMIC, the conditional probability of PTSD given a traumatic event and the strength of associations between traumatic events and other psychiatric disorders.
\end{abstract}

\section{Method}

Our sample contained a mix of 3995 twins and 2019 nontwins. We asked participants about nine different traumatic exposures, including the category 'other', but excluding sexual trauma.

\section{Results}

Traumatic events were reported by $36.3 \%$ of participants and lifetime PTSD was present in $2.0 \%$. Prevalence of non-PTSD lifetime diagnosis was $19.1 \%$. Of people who had experienced three or more traumatic events, $13.3 \%$ had lifetime PTSD and $40.4 \%$ had a non-PTSD psychiatric diagnosis.

\section{Conclusions}

Despite high rates of exposure to trauma, this population had lower rates of PTSD than high-income populations, although the prevalence might have been slightly affected by the exclusion of sexual trauma. There are high rates of non-PTSD diagnoses associated with trauma exposure that could be considered in interventions for trauma-exposed populations. Our findings suggest that there is no unique relationship between traumatic experiences and the specific symptomatology of PTSD.

\section{Declaration of interest}

M.H. receives salary support from the National Institute for Health Research (NIHR) Mental Health Biomedical Research Centre at South London and Maudsley NHS Foundation Trust and King's College London and is Director of the Centre. The views expressed are those of the author(s) and not necessarily those of the NHS, the NIHR or the Department of Health.

\section{Copyright and usage}

(C) The Royal College of Psychiatrists 2014. This is an open access article distributed under the terms of the Creative Commons Attribution (CC BY) licence.
Post-traumatic stress disorder (PTSD) is controversial for several reasons. ${ }^{1}$ First, critics have noted the long list of potential PTSD symptoms in diagnostic manuals, leading to the potential for diagnostic inflation, ${ }^{2}$ and high rates of comorbidity with related psychiatric disorders such as anxiety and affective disorders. ${ }^{3}$ Second, PTSD is unusual in psychiatric classification because, unlike other disorders, it requires both a symptom profile and a cause (i.e. trauma - criterion A in DSM-IV ${ }^{4}$ ) to be present. The 'internal logic's of the PTSD construct assumes an exclusive causal relationship between PTSD symptoms and trauma. The centrality of traumatic events to PTSD has been further emphasised in DSM $-5,{ }^{6}$ in which PTSD has been moved from anxiety disorders to trauma and stress-related illnesses. Successive versions of DSM have weakened criterion A without validating its specificity to PTSD symptoms ${ }^{2,7}$ and the diagnosis is now clinically and in research widely used for more common but less extreme events than originally intended, such as friendship break-ups and exposure to television programmes. ${ }^{8}$ This loosening of criterion $\mathrm{A}$ is also perhaps an expression of the difficulties inherent in applying it - trauma is defined by subjective experience and there is considerable variation in individual responses to potentially traumatic exposures, making the operationalisation of criterion A difficult. Finally, some commentators ${ }^{9,10}$ have remarked how PTSD, more than other psychiatric disorders, owes its origins to a political need - i.e. to characterise the disorders expressed by veterans returning from the Vietnam war, and can be viewed as a socially sanctioned sick role for individuals who have experienced trauma.
Prevalence estimates of PTSD in general population community studies in high-income countries vary widely. In a US national sample, lifetime prevalence of PTSD was $7.8 \%{ }^{3}$ In an urban study in Detroit $9.2 \%$ of the population had lifetime PTSD. ${ }^{11}$ Population studies that have assessed 12-month prevalence found it to be $1.3 \%$ in Australia ${ }^{12}$ and $1-2.2 \%$ in a study of young people (aged 14-24) in Germany. ${ }^{13}$ A recent survey in South East London ${ }^{14}$ suggested prevalence of PTSD symptoms in the past month to be closer to $5.5 \%$. Few general population studies of PTSD exist in low-and middle-income countries (LMICs). ${ }^{15}$ Most studies have focused on 'high-risk' populations defined by exposure to trauma. In Sri Lanka, the setting for the present study, prevalence in such high-risk populations, exposed to the Civil War (1983-2009), the tsunami (2004) or prolonged internal displacement, indicate prevalence estimates varying from 2.8 to $40 \% .{ }^{16-19}$ Following the 2004 tsunami, PTSD in Sri Lanka became a high-profile and controversial international issue. ${ }^{20}$ Despite this, PTSD has not yet been reported in general population samples. Studies on the prevalence of PTSD are difficult to interpret without parallel information on the prevalence of criterion A exposures (traumas) and information on the conditional probability of developing PTSD in the presence of trauma. ${ }^{21}$ Further, because comorbidity is high, it is desirable to understand the extent to which PTSD symptoms are a unique and specific response to criterion A traumas as opposed to one of a number of potential psychiatric responses. For that reason we compare conditional probabilities of other psychiatric disorders to such traumas. The aims of this paper therefore were: 
(a) to estimate the prevalence of criterion A traumas and lifetime PTSD in a Sri Lankan population; (b) to determine the conditional probability of PTSD given any specific traumatic event; and (c) to determine the strength of associations between traumatic events and other psychiatric disorders.

\section{Method}

\section{Study design and participants}

The Colombo Twin And Singleton Study (CoTASS) is a population-based twin study with a comparable non-twin sample. Full details of the design and implementation of the study are described elsewhere. ${ }^{22}$ The study took place in the Colombo District of Sri Lanka, an area with a population of 2.2 million that includes the island's capital. The district has a mixture of urban and rural populations with $45 \%$ of the population officially designated as living in rural and suburban communities. The area has a diverse population, including people who are more Westernised than in other areas of Sri Lanka. It is also attracts economic migrants and, at the time of the research, individuals displaced by the Sri Lankan Civil War and the tsunami.

The annual update of the electoral register consists of a household census conducted by a local official, the Grama Nildari. We added a question asking whether the householder knew of any twins, and identified 19302 individual twins by this method. Of these, we randomly selected 4387 twins to take part in the project on common mental disorders. A total of 4024 (91.7\%) participated, and interviews were completed for 3995. In addition, we conducted a parallel study of non-twins, randomly sampled from the same local areas from which twins were recruited, with the purpose of identifying any differences between twins in terms of psychiatric morbidity. A total of 2311 non-twins were selected and eligible to participate, of whom 2019 (87.4\%) consented and were interviewed. The twin and non-twin samples had similar gender profiles, ${ }^{22}$ although non-twins tended to be older. We included all consenting individuals aged 15 years or older who spoke sufficient Sinhala to understand the interview. Interviews took place between 2006 and 2007, when Sri Lanka had been experiencing violent civil war for over 30 years. There have been uprisings and bombing attacks in Colombo, and at times a strong military presence. Although people in Colombo have been affected by the tsunami of 2004, direct involvement was not on the same scale as on the south and east coasts of the island.

\section{Data collection}

Research workers with high-school education (A-level equivalent) visited the participants' homes, and twins were interviewed separately. We used the Composite International Diagnostic Interview (CIDI), ${ }^{23}$ a structured diagnostic interview for use by lay interviewers. This gives DSM/ICD diagnoses of mental disorders. We used lifetime DSM-IV definitions. ${ }^{4}$ We defined our outcome as those who met full criteria for CIDI lifetime PTSD. However, we used a modified version of criterion A traumatic events (Table 2) because for a population study where we were contacting people for the first time the local experts were concerned that asking about sexual trauma would not be acceptable. Consequently, we were unable to include rape and sexual abuse in the list of trauma exposures. In addition to PTSD we collected information on affective disorders, anxiety disorders and substance use disorders (alcohol and nicotine dependence). We used the Bradford Somatic Inventory ${ }^{24}$ that provides a cut-off indicating likely somatoform symptoms.

Measures were translated with great care to ensure they were culturally appropriate. Thirteen bilingual twins (contacted from the registry) and other Sri Lankans fluent in English and Sinhala were asked to translate components of the interview. Each component was translated at least twice independently. The translations were then reviewed in group meetings consisting of seven bilingual healthcare professionals with training in mental health. A scholar in Sinhala also checked the translation. The translation aimed to find forms of words in Sinhala that best described the concepts of interest and where the questions when translated seemed cumbersome, they might be broken down into two component items for clarity. The interviews were then trialed by field workers and four individuals with no connection to the study, in order to confirm that lay people could understand it.

The importance of the contextual framing of questions in the PTSD questionnaire has been suggested in previous studies. ${ }^{3}$ Researchers may be more likely to find a high prevalence of PTSD in the context of a survey that frames questions in terms of exposure to conflict or natural disaster. This community-based study includes the PTSD questionnaire as part of a broader questionnaire, where the primary focus was not trauma.

The study received approval from the Institute of Psychiatry, King's College London Research Ethics Committee, the Ethical Review Committee, University of Sri Jayewardanepura and the World Health Organization's Research Ethics Committee.

\section{Statistical analysis}

A database was constructed in SPSS version 14 for Mac. The descriptive statistics were performed in Stata version 11. All analyses were corrected for non-independence of observations by using robust (sandwich) standard error estimation with the cluster command in Stata, family ID. We used logistic regression to derive odds ratios and $95 \%$ confidence intervals to express associations.

\section{Results}

\section{The prevalence of significant traumas in an urban LMIC population}

Among our sample of 6014 participants, 36.3\% (95\% CI 35.137.5) reported experiencing at least one traumatic event. Lifetime post-traumatic stress disorder (DSM-IV) ${ }^{4}$ was present in $2.0 \%$ (95\% CI 1.6-2.3) of the sample. Table 1 describes associations of trauma and PTSD (for a more detailed version of this Table see online Table DS1). Trauma was strongly associated with male gender, but was not associated with age, marital status or socioeconomic status (SES). By contrast, those with trauma who had PTSD tended to be female, had higher deprivation scores, were more likely to have been previously married, and were more likely to be unable to work (for example, unemployed or sick). The final column of Table 1 shows the association between various sociodemographic variables and PTSD in the entire population, and shows a broadly similar pattern - women, the most deprived, those previously married and those unable to work were most likely to have PTSD.

Analyses of the age at which traumatic events occurred showed that 75 traumatic events were reported as occurring by the age of 9 years; none of these participants had lifetime PTSD. Between the ages of 10-17 years, 385 individuals reported traumatic events, of whom 17 had lifetime PTSD (conditional probability $(\mathrm{CP})=5 \%)$. The age at which events had the highest positive predictive value of going on to PTSD was between 31 and 39 years of age $(\mathrm{CP}=8 \%)$. In the oldest age range, $60-81$ years, 42 events were recorded, and one event was associated with PTSD $(\mathrm{CP}=2 \%)$. 


\begin{tabular}{|c|c|c|c|c|c|c|}
\hline Variable & $\begin{array}{l}\text { Population } \\
(n=6014)\end{array}$ & $\begin{array}{l}\text { Trauma, } n(\%) \\
(n=2181)\end{array}$ & $\begin{array}{c}\text { Trauma, univariate } \\
\text { OR }(95 \% \mathrm{Cl})\end{array}$ & $\begin{array}{l}\text { PTSD, } n(\%) \\
(n=119)\end{array}$ & $\begin{array}{l}\text { PTSD in trauma-exposed } \\
\text { population, unadjusted } \\
\text { OR }(95 \% \mathrm{Cl})\end{array}$ & $\begin{array}{c}\text { PTSD in whole } \\
\text { population, unadjusted } \\
\text { OR }(95 \% \mathrm{Cl})\end{array}$ \\
\hline \multicolumn{7}{|l|}{ Gender } \\
\hline Male & 2765 & $1224(44.3)$ & 1 & $44(1.6)$ & 1 & 1 \\
\hline Female & 3247 & $957(29.5)$ & $0.53(0.47-0.59)$ & $75(2.3)$ & $2.28(1.55-3.36)$ & $1.46(1.00-2.14)$ \\
\hline \multicolumn{7}{|l|}{ Age (quintiles) } \\
\hline $16-23$ & 1285 & $445(34.6)$ & 1 & $18(1.4)$ & 1 & 1 \\
\hline $24-30$ & 1138 & 391 (34.4) & $0.99(0.82-1.19)$ & $25(2.2)$ & $1.63(0.87-3.07)$ & $1.58(0.86-2.96)$ \\
\hline $31-39$ & 1253 & 495 (39.5) & $1.23(1.03-1.47)$ & $28(2.2)$ & $1.43(0.76-2.67)$ & $1.61(0.87-2.99)$ \\
\hline $40-51$ & 1200 & $450(37.5)$ & $1.13(0.94-1.36)$ & $23(2.3)$ & $1.51(0.81-2.84)$ & $1.62(0.87-3.01)$ \\
\hline $52+$ & 1138 & $400(35.2)$ & $1.02(0.85-1.23)$ & $21(1.9)$ & $1.31(0.68-2.53)$ & $1.32(0.69-2.53)$ \\
\hline \multicolumn{7}{|l|}{ Quintiles deprivation } \\
\hline Lowest quintile & 1198 & $451(37.7)$ & 1 & $18(1.5)$ & 1 & 1 \\
\hline Second & 1205 & $411(34.1)$ & $0.85(0.72-1.02)$ & $19(1.6)$ & $1.17(0.61-2.27)$ & $1.05(0.55-2.02)$ \\
\hline Third & 1202 & 412 (34.3) & $0.86(0.73-1.03)$ & $26(2.2)$ & $1.62(0.86-3.04)$ & $1.45(0.78-2.68)$ \\
\hline Fourth & 1202 & $466(38.8)$ & $1.05(0.88-1.25)$ & $24(2.0)$ & $1.30(0.70-2.44)$ & $1.34(0.72-2.47)$ \\
\hline Highest quintile & 1202 & $441(36.7)$ & $0.96(0.81-1.14)$ & $32(2.7)$ & $1.88(1.04-3.40)$ & $1.79(1.00-3.21)$ \\
\hline \multicolumn{7}{|l|}{ Employment } \\
\hline Full time & 2646 & $1051(39.7)$ & 1 & $41(1.5)$ & 1 & 1 \\
\hline Part-time/seasonal & 381 & $182(47.8)$ & $1.38(1.11-1.73)$ & $13(3.4)$ & $1.89(1.00-3.59)$ & $2.24(1.20-4.20)$ \\
\hline Student & 567 & 189 (33.3) & $0.76(0.59-0.76)$ & $8(1.4)$ & $1.09(0.50-2.34)$ & $0.91(0.43-1.94)$ \\
\hline Unable to work & 145 & $54(37.2)$ & $0.90(0.63-1.28)$ & $7(4.8)$ & $3.66(1.56-8.60)$ & $3.22(1.42-7.33)$ \\
\hline Home-maker ${ }^{\mathrm{b}}$ & 2225 & $682(30.7)$ & $0.67(0.59-0.76)$ & $48(2.2)$ & $1.87(1.22-2.87)$ & $1.40(0.92-2.13)$ \\
\hline Other & 38 & $20(52.6)$ & $1.69(0.85-3.35)$ & $2(5.3)$ & $2.73(0.65-11.40)$ & $3.53(0.85-14.65)$ \\
\hline \multicolumn{7}{|l|}{ Marital status } \\
\hline Married & 3570 & $1360(38.1)$ & 1 & $70(2.0)$ & 1 & 1 \\
\hline Single & 2059 & $694(33.7)$ & $0.83(0.73-0.93)$ & $31(1.5)$ & $0.86(0.56-1.33)$ & $0.76(0.50-1.17)$ \\
\hline Previously married & 375 & 127 (33.9) & $0.83(0.66-1.05)$ & $18(4.8)$ & $3.03(1.74-5.30)$ & $2.52(1.48-4.29)$ \\
\hline
\end{tabular}

\section{Conditional probability of PTSD following traumatic events}

The conditional probability of developing PTSD and any psychiatric disorder (including depression or dysthymia, anxiety disorders and alcohol dependence) for each criterion A event are given in Table 2. Individual events had a wide variation in prevalence $(0.9-14.8 \%)$. The most frequently experienced traumatic events among participants were life-threatening accident (14.8\%), witnessing intentional or accidental death/ injury to another (13.1\%) and natural disaster (8.1\%). Conditional probabilities of developing PTSD in these groups were $6.0 \%, 4.1 \%$ and $6.4 \%$, respectively. Life-threatening accidents were experienced by the largest number (53) of people with PTSD (44.5\%). Only $1.4 \%$ of the population reported experiencing trauma as a result of experience as a combatant; in this small group the $\mathrm{CP}$ equalled $6.9 \%$. The three categories with the highest conditional probabilities were experiences of intended harm to self. They were endorsed by only a small percentage of the population $0.9-3.6 \%$. These were 'torture/terrorism' $(\mathrm{CP}=21.2 \%)$, 'physical attack' ( $\mathrm{CP}=15.5 \%)$, 'threatened by weapon/kidnapped' $(\mathrm{CP}=14.7 \%)$. Although the individual traumas show strong associations with PTSD, they were also associated with other psychiatric disorders, as described in Table 2. For any trauma, the proportion of individuals with other psychiatric disorders was considerably greater than for PTSD. The traumas with the highest prevalence of psychiatric disorders were also those that involved intended harm to the individual.

The bottom half of Table 2 groups the trauma-exposed population according to the number of traumatic events experienced. Consistent with other studies, ${ }^{25}$ Table 2 shows the increase in the prevalence of PTSD as the number of traumatic experiences reported increases. Of participants who reported one event, 3.4\% had PTSD, whereas of people who have experienced three or more events, $13.3 \%$ had experienced lifetime PTSD. Prevalence of non-PTSD psychiatric comorbidity also increased with increasing numbers of traumatic events, with $40.4 \%$ of the population who had experienced three events or more having a non-PTSD psychiatric diagnosis. Overall, there is a higher prevalence of non-PTSD psychiatric disorders in individuals exposed to trauma than in the general population.

\section{Non-PTSD psychiatric illnesses among participants with PTSD}

Psychiatric comorbidity among participants with PTSD was high (Table 3): a total of 80 people (70\%) with PTSD had at least one additional DSM-IV comorbidity. Comorbidity of PTSD with depression $(\mathrm{OR}=9.2, \quad 95 \% \quad \mathrm{CI} \quad 6.3-13.6, \quad P<0.001)$, panic $(\mathrm{OR}=25.3, \quad 95 \% \quad \mathrm{CI} \quad 11.2-57.2, \quad P<0.0001)$, any anxiety ( $\mathrm{OR}=7.2,95 \% \mathrm{CI} 4.9-10.7, P<0.001)$ or alcoholism (men only) $(\mathrm{OR}=8.0,95 \%$ CI $4.4-14.5, \quad P<0.001)$ were most notably increased in this population.

\section{Discussion}

Despite increased injuries from road traffic accidents, interpersonal violence, and war in middle-income countries, ${ }^{26}$ our study population reported a lower prevalence of traumatic events and a lower prevalence of PTSD than the majority of high-income community studies. ${ }^{3,14}$ The greatest prevalence of psychiatric illness among the trauma-exposed population was non-PTSD psychiatric diagnosis. 
Table 2 Conditional probabilities of post-traumatic stress disorder (PTSD) and non-PTSD psychiatric diagnoses for each traumatic event

\begin{tabular}{|c|c|c|c|}
\hline Traumatic event & $\begin{array}{l}\text { Population with } \\
\text { event, } n(\%)\end{array}$ & $\begin{array}{l}n \text { (\%) with each } \\
\text { event with PTSD }\end{array}$ & $\begin{array}{l}n(\%) \text { with each event } \\
\text { with other diagnoses }\end{array}$ \\
\hline No event & 3828 (63.7) & $0^{\mathrm{b}}$ & $590(16.7)$ \\
\hline Tortured or terrorised & $52(0.9)$ & $11(21.2)$ & $24(46.2)$ \\
\hline Physical attack & $219(3.6)$ & $34(15.5)$ & $100(45.7)$ \\
\hline Threatened with weapon or kidnapped & $157(2.6)$ & $23(14.7)$ & $48(30.6)$ \\
\hline Other stressful event & $339(5.6)$ & $33(9.7)$ & 115 (33.9) \\
\hline Shock of event to someone else & $355(5.9)$ & $29(8.2)$ & $93(26.2)$ \\
\hline Involved in combat & $87(1.4)$ & $6(6.9)$ & $15(17.2)$ \\
\hline Natural disaster & $486(8.1)$ & $31(6.4)$ & $141(29.0)$ \\
\hline Life-threatening accident & $891(14.8)$ & $53(6.0)$ & $254(28.5)$ \\
\hline Witnessed killing or accident & $786(13.1)$ & $32(4.1)$ & $186(23.7)$ \\
\hline \multicolumn{4}{|l|}{ Cumulative events } \\
\hline None & $3828(63.7)$ & $0^{\mathrm{b}}$ & $590(16.7)$ \\
\hline 1 & $1393(23.2)$ & $47(3.4)$ & $309(22.2)$ \\
\hline 2 & $517(8.6)$ & $36(7.0)$ & $142(27.5)$ \\
\hline $3+$ & $270(4.5)$ & $36(13.3)$ & $109(40.4)$ \\
\hline
\end{tabular}

\begin{tabular}{|c|c|c|c|c|c|c|c|}
\hline $\begin{array}{l}\text { DSM-IV lifetime } \\
\text { diagnosis }\end{array}$ & $\begin{array}{l}n(\%) \text { affected } \\
\text { in whole } \\
\text { population }\end{array}$ & $\begin{array}{l}n(\%) \text { affected } \\
\text { with any } \\
\text { trauma }\end{array}$ & $\begin{array}{l}\text { Unadjusted OR } \\
(95 \% \mathrm{Cl}) \text { for } \\
\text { any trauma }\end{array}$ & $P$ & $\begin{array}{l}n(\%) \text { with PTSD } \\
\text { comorbid for } \\
\text { diagnosis }\end{array}$ & $\begin{array}{l}\text { Unadjusted OR } \\
\text { (95\% CI) of diagnosis } \\
\text { by PTSD status }\end{array}$ & $P$ \\
\hline Depression $^{a}$ & $397(6.6)$ & $217(10.0)$ & $2.24(1.82-2.76)$ & $<0.001$ & $44(37.0)$ & $9.23(6.27-13.59)$ & $<0.001$ \\
\hline Dysthymia & $66(1.2)$ & $52(2.4)$ & $2.90(1.85-4.55)$ & $<0.001$ & $17(14.4)$ & $14.83(8.41-26.17)$ & $<0.001$ \\
\hline Any anxiety disorder & $546(9.1)$ & 270 (12.4) & $1.82(1.52-2.18)$ & $<0.001$ & $46(40.0)$ & $7.22(4.89-10.65)$ & $<0.001$ \\
\hline Generalised anxiety disorder & $239(4.0)$ & $138(6.3)$ & $2.49(1.91-3.26)$ & $<0.001$ & 29 (12.18) & $9.16(5.90-14.22)$ & $<0.001$ \\
\hline Agoraphobia & $97(1.6)$ & $50(2.3)$ & $1.17(1.06-1.30)$ & 0.002 & $15(12.6)$ & $1.79(1.55-2.07)$ & $<0.001$ \\
\hline Social phobia & $105(1.8)$ & $60(2.8)$ & $2.38(1.59-3.54)$ & $<0.001$ & $11(9.24)$ & $6.28(3.27-12.06)$ & $<0.001$ \\
\hline Simple phobia & $356(5.9)$ & $177(8.1)$ & $1.68(1.36-2.09)$ & $<0.001$ & $28(23.5)$ & $5.25(3.39-8.15)$ & $<0.001$ \\
\hline Panic disorder & $28(0.5)$ & $20(0.9)$ & $4.42(1.94-10.06)$ & $<0.001$ & $9(7.6)$ & $25.28(11.18-57.16)$ & $<0.001$ \\
\hline Alcohol dependence ${ }^{b}$ & $111(1.9)$ & $66(3.0)$ & $1.27(1.16-1.39)$ & $<0.001$ & $14(11.8)$ & $8.00(4.38-14.46)$ & $<0.001$ \\
\hline Somatisation (BSI >12) & $388(6.5)$ & $179(8.2)$ & $1.55(1.25-1.92)$ & $<0.001$ & $28(23.5)$ & $4.74(3.08-7.31)$ & $<0.001$ \\
\hline Any psychiatric disorder & $1152(19.2)$ & $560(25.8)$ & $1.90(1.67-2.17)$ & $<0.001$ & $80(69.6)$ & $10.28(6.8-15.54)$ & $<0.001$ \\
\hline
\end{tabular}

\section{Trauma exposure in Sri Lanka}

The prevalence of traumatic events reported in our population was $36.3 \%$. Community studies in the USA report the prevalence of traumatic events to be higher, between $36.7 \%$ and $92.2 \%{ }^{27}$ Variation in prevalence of traumatic events may partly be explained by the diagnostic questionnaires used across studies. The number of events defined as traumatic in a questionnaire is likely to affect disclosure. This may be particularly true of highly stigmatised events, for example it has been found that unless individuals are asked about sexual abuse, this exposure is underreported. Kessler et al (1995), ${ }^{3}$ Breslau et al $(1998)^{21}$ and de Vries \& Olff $(2009)^{28}$ used expanded versions of the Traumatic Events Questionnaire, with up to 36 specified traumatic events. The questionnaires applied in our study, and by Breslau et al $(1991)^{11}$ specify just nine different traumatic events (Table 2).

We removed sexual trauma from the Trauma Events Questionnaire because of concerns about social acceptability in a community survey whose main emphasis was not on PTSD. Although sexual trauma may have been included in response to the category of 'other', it is probable that trauma prevalence was underestimated particularly in the female population. This may partially explain why the overall prevalence of traumatic events was lower $(36.3 \%)$ in our sample than in US community samples $(36.7-92.2 \%){ }^{27}$

There are likely to be differences in the characteristics that define events as traumatic across populations. ${ }^{9}$ Many factors may change the ways in which events are expected to be, or are accepted as, 'traumatic.' Reports of lifetime events reduce in older age, suggesting that reported lifetime traumatic events do not represent lifetime exposure. This has been noted in other crosssectional studies of traumatic events. ${ }^{3}$

\section{PTSD in Sri Lanka}

Why is the prevalence of PTSD in our study $(2.0 \%)$ lower than estimates in Western populations? It has been suggested that PTSD is a relatively rare and atypical response to trauma. ${ }^{29}$ The prevalence of traumatic events $(36.3 \%)$ suggests that the low prevalence of PTSD in this study population is not solely explained by low exposure to trauma. This study's gender and age distributions of PTSD are consistent with findings in other papers. 
The removal of sexual trauma from the study questionnaire prevented individuals who had experienced sexual trauma from meeting the Criterion A of a trauma event required to diagnose PTSD unless they endorsed the 'other' category. This is likely to disproportionately underestimate the prevalence of PTSD in the female population, which has been suggested by findings that rape and sexual molestation were the traumas most commonly associated with PTSD in women in the USA. ${ }^{3}$ However, despite our probable underestimation, it is unlikely that the undetected prevalence of sexual trauma would greatly alter the relatively low prevalence of PTSD in our study compared with the prevalence found in US studies. ${ }^{3,21}$

Commentators have noted that the diagnosis of PTSD, derived in the aftermath of the Vietnam war, does not necessarily cross cultures and is too readily assumed to be linked to a status of victimhood. ${ }^{30}$ Ehlers \& Clark $^{31}$ and Brewin $e t a l^{32}$ suggest that individual factors, including individual appraisals of trauma and its aftermath may be more predictive of PTSD than the objective degree of trauma exposure. External attitudes towards traumaexposed individuals may also influence development of PTSD following traumatic events ${ }^{33}$ and good group leadership may reduce an individual's risk of PTSD following a traumatic event. $^{34}$

\section{Local variations in PTSD}

Researchers have argued that cultures influence the shape of PTSD over time. ${ }^{35}$ In Sri Lanka responses to events ${ }^{33}$ and cognitive styles $^{36}$ have been found to influence the prevalence of PTSD. Studies of PTSD suggest that symptomatology varies across geographic locations. A study of tsunami-affected populations in Asia found that post-traumatic stress symptoms were common, but functional impairment and avoidance behaviours were absent. ${ }^{37}$ Variations in correlations of symptoms may help to partly explain the low prevalence of individuals who meet full criteria for PTSD in our sample.

\section{PTSD in the non trauma-exposed population}

As a result of PTSD's diagnostic criteria, PTSD was not assessed in individuals who did not report a traumatic event in criterion A. Therefore, as in the majority of studies of PTSD, we are unable to estimate PTSD symptom prevalence among people who do not endorse criterion A. Recently a UK-based study assessed PTSD in individuals who had experienced non-traumatic life events, and found that non-traumatic life events were more predictive of symptoms of PTSD than traumatic events. ${ }^{38}$ Further studies have demonstrated the frequent occurrence of PTSD symptoms among people who had not experienced Criterion A life stressors. ${ }^{39}$ These findings challenge the 'internal logic ${ }^{5}$ of PTSD.

\section{Conditional probability of events}

There is agreement across studies about the kinds of traumatic event that are most likely to cause PTSD. The highest probability of developing PTSD has been reported in civilians who have experienced interpersonal violence, rape or torture, or who have been threatened with a weapon. ${ }^{27}$ Breslau reported that the conditional probability for these events was $11-20 \% .{ }^{27}$ Among our study participants, traumas involving interpersonal violence also have the highest conditional probabilities for developing PTSD $\quad(C P=14.7-21.2 \%)$. Studies repeatedly show that experiences of interpersonal violence in inner-city and urban life have a high predictive value of PTSD.

\section{PTSD among combatants}

Combatants from our sample are not representative of combatants in Sri Lanka. Sri Lanka has endured decades of civil war. Although Colombo district is not an area highly exposed to conflict it has experienced terrorist bombings and threats. Our study population includes small numbers of inhabitants who have fought in the civil war as well as internal migrants who have moved to Colombo from war affected areas. A total of $21 \%$ reported that they had been affected by conflict, but only $2.6 \%$ of the population reported being combatants in conflict and only $1.4 \%$ reported a combat-related trauma. The conditional probability of developing PTSD among participants exposed to traumatic events in combat was relatively low, just $6.9 \%$, compared with $5.5 \%$ in the entire trauma-exposed population, and a conditional probability of non-PTSD psychiatric comorbidity of $17.2 \%$, compared with $16.7 \%$ among those with no event. Hanwella's study found a prevalence of PTSD in Sri Lanka in the special forces of $1.9 \%$ and among the regular forces of $2.9 \%{ }^{40}$

\section{PTSD in the tsunami-exposed population}

The 2004 tsunami in Sri Lanka caused over 35000 reported deaths, and over 500000 people were displaced. Colombo was not severely affected by the tsunami, but its population has been exposed to floods, drought, landslides and cyclones and includes internal migrants from tsunami-affected areas. Four percent of participants were directly exposed to the tsunami, and a total of $26 \%$ were affected by the disaster, for example by being in an affected area or by losing a family member or friend. Participants who have experienced exposure to natural disaster had a relatively low conditional probability of PTSD of $6.4 \%$ and a much higher conditional probability for non-PTSD psychiatric morbidity of $29.0 \%$.

\section{Non-PTSD psychiatric morbidity in trauma-exposed populations}

There is controversy over whether the psychiatric needs of trauma-exposed populations can be accurately addressed using the PTSD construct, or indeed the new DSM category of 'trauma and stress related illnesses.5,9,41 Degree of exposure to trauma is associated with risk of PTSD $^{27}$ but also non-PTSD psychiatric diagnosis. ${ }^{29}$ Our results support the finding that non-PTSD psychiatric diagnosis have a higher prevalence than PTSD in trauma-exposed populations - for example, of those with three or more traumatic events $40.4 \%$ had a non-PTSD psychiatric diagnosis and $13.3 \%$ had PTSD. This suggests that the domination of PTSD as the main psychiatric consequence of trauma in Sri Lanka is misguided and mental public health following traumatic events should have a wider focus that includes depression, anxiety, somatic symptoms and substance misuse.

\section{Strengths and weaknesses}

The study had an exceptionally high participation rate and thus avoided some of the systematic underreporting of psychiatric disorders inherent in much of psychiatric epidemiology. ${ }^{42}$ We used a rigorous diagnostic interview to ascertain PTSD, which was carefully adapted using bilingual appraisers. The main weakness of this study was its cross-sectional design. Recall bias and reverse causality cannot be discarded when considering the association between traumatic events and mental disorders. As discussed, sexual trauma was excluded from the questionnaire; this probably led to an underestimation of trauma and PTSD. Individuals who have experienced sexual trauma may be more 
likely to be captured in the non-trauma-exposed population, under affective and anxiety disorders, simply because they are less likely to endorse criterion A. This may lead to an overestimation of anxiety and depression in the non-trauma exposed group.

Although the use of a twin sample is unusual, it was ascertained from a rigorously defined population with a parallel non-twin comparison group. The two groups showed no difference in prevalence of PTSD and appropriate measures were taken to account for non-independence within-twin pairs within the sample.

In conclusion, we demonstrate a low prevalence of PTSD, despite frequent reporting of traumatic events, an extremely high comorbidity of PTSD (70\%), and similar relationships between PTSD and non-PTSD symptoms. These results challenge PTSD as a specific response to trauma and indicate that, in this Sri Lankan sample, other, more prevalent psychiatric disorders, such as depression, anxiety, somatic symptoms and substance misuse, have a higher population impact in the trauma-exposed community population. This suggests that, in this study population, there is no unique relationship between traumatic experiences and the specific symptomatology of PTSD. These findings call into question the face validity of a diagnosis that couples aetiology with phenomenology. We suggest that until we have a better understanding of psychopathology, psychiatric classification decouples these two radically different entities.

Sarah Dorrington, Department of Psychological Medicine, Institute of Psychiatry King's College London, UK; Helena Zavos, PhD, MRC Social, Genetic and Developmental Psychiatry Centre, Institute of Psychiatry, King's College London, UK; Harriet Ball, PhD, BMBCh, Faculty of Medicine, Imperial College London, UK; Peter McGuffin, PhD, Fruhling Rijsdijk, PhD, MRC Social, Genetic and Developmental Psychiatry Centre, Institute of Psychiatry, King's College London, UK Sisira Siribaddana, MBBS, MD, Department of Medicine Faculty of Medicine and Allied Sciences, Rajarata University of Sri Lanka, and Institute of Research and Development Sri Lanka; Athula Sumathipala, MD, PhD, Research Institute for Primary Care and Health Sciences, Keele University, and Department of Health Service and Population Research, King's College London Honorary Director, and Institute for Research and Development Sri Lanka; Matthew Hotopf, PhD, Department of Psychological Medicine, Institute of Psychiatry, King's College London, UK.

Correspondence: Matthew Hotopf, Department of Psychological Medicine, Institute of Psychiatry, Weston Education Centre, Cutcombe Rd, London SE5 9RJ. Email: matthew.hotopf@kcl.ac.uk

First received 14 Nov 2013, final revision 20 May 2014, accepted 6 Jun 2014

\section{Funding}

The research was funded by Wellcome Trust.

\section{References}

1 Maercker A, Brewin CR, Bryant RA, Cloitre M, van Ommeren M, Jones LM, et al. Diagnosis and classification of disorders specifically associated with stress: proposals for ICD-11. World Psychiatry 2013; 12: 198-206.

2 Rosen GM, Spitzer RL, McHugh PR. Problems with the post-traumatic stress disorder diagnosis and its future in DSM-V. Br J Psychiatry 2008; 192 3-4.

3 Kessler RC, Sonnega A, Bromet $\mathrm{E}$, Hughes $\mathrm{M}$, Nelson $\mathrm{CB}$, posttraumatic stress disorder in the national comorbidity survey. Arch Gen Psychiatry 1995; 52: 1048.

4 American Psychiatric Association. Diagnostic and Statistical Manual of Mental Disorder (4th edn) (DSM-IV). APA, 1994

5 Young A \& Breslau N. Troublesome memories: reflections on the future. J Anxiety Disord 2007; 21: 230-2.

6 American Psychiatric Association. Diagnostic and Statistical Manual of Mental Disorder (5th edn) (DSM-5). APA, 2013.

7 Breslau N, Kessler RC. The stressor criterion in DSM-IV posttraumatic stress disorder: an empirical investigation. Biol Psychiatry 2001; 50: 699-704.
8 Rosen, Lilienfeld. Posttraumatic stress disorder: an empirical evaluation of core assumptions. Clin Psychol Rev 2008; 28: 837-68.

9 Jones E, Wessely S. A paradigm shift in the conceptualization of psychological trauma in the 20th century. J Anxiety Disord 2007; 21 $164-75$.

10 Pupavac V. War on the couch: the emotionology of the new international security paradigm. Eur J Soc Theory 2004; 7: 149-70.

11 Breslau N, Davis GC, Andreski P, Peterson E. Traumatic events and posttraumatic stress disorder in an urban population of young adults. Arch Genl Psychiatry 1991; 48: 216-22.

12 Creamer M, Burgess $P$, McFarlane AC. Post-traumatic stress disorder: findings from the Australian National Survey of Mental Health and Well-being. Psychol Med 2001; 31: 1237-47.

13 Perkonigg A, Kessler RC, Storz S, Wittchen HU Traumatic events and posttraumatic stress disorder in the community: prevalence, risk factors and comorbidity. Acta Psychiatr Scand 2000; 101: 46-59.

14 Frissa S, Hatch SL, Gazard B, Fear NT, Hotopf M. Trauma and current symptoms of PTSD in a South East London community. Soc Psychiatry Psychiatr Epidemiol 2013, 48: 1199-209.

15 Patel V, Sumathipala A. International representation in psychiatric literature survey of six leading journals. Br J Psychiatry 2001; 178: 406-9.

16 Hollifield M, Hewage C, Gunawardena CN, Kodituwakku P, Bopagoda K, Weerarathnege K. Symptoms and coping in Sri Lanka 20-21 months after the 2004 tsunami. Br J Psychiatry 2008; 192: 39-44.

17 Somasundaram DJ, Sivayokan S. War trauma in a civilian population. Br J Psychiatry 1994; 165: 524-7.

18 Catani C, Jacob N, Schauer E, Kohila M, Neuner F. Family violence, war, and natural disasters: a study of the effect of extreme stress on children's mental health in Sri Lanka. BMC Psychiatry 2008; 8: 33

19 Siriwardhana C, Adikari A, Pannala G, Siribaddana S, Abas M, Sumathipala A, et al. Prolonged Internal displacement and common mental disorders in Sri Lanka: the COMRAID study. PLoS One 2013; 22: 8.

20 Sumathipala A, Siribaddana S. Research and clinical ethics after the tsunami: Sri Lanka. Lancet 2005; 366: 1418-20.

21 Breslau N, Kessler RC, Chilcoat HD, Schultz L, Davis GC, Andreski P. Trauma and posttraumatic stress disorder in the community the 1996 Detroit Area Survey of Trauma. Arch Gen Psychiatry 1998; 55: 626.

22 Siribaddana $\mathrm{SH}$, Ball $\mathrm{H}$, Hewage SN, Glozier N, Kovas $\mathrm{Y}$, Dayaratne $\mathrm{D}$, et al. Colombo Twin and Singleton Study (COTASS): a description of a population based twin study of mental disorders in Sri Lanka. BioMed Central Psychiatry 2008; 8: 49.

23 Division of Mental Health. CIDI-Core. Composite International Diagnostic Interview, Core version 1.0. WHO, 1990.

24 Mumford DB, Bavington JT, Bhatnagar KS, Hussain Y, Mirza S, Naraghi MM. The Bradford Somatic Inventory. A multi-ethnic inventory of somatic symptoms reported by anxious and depressed patients in Britain and the Indo-Pakistan subcontinent. Br J Psychiatry 1991; 158: 379-86.

25 Breslau N, Chilcoat, HD, Kessler RC, Davis, GC. Previous exposure to trauma and PTSD effects of subsequent trauma: results from the Detroit Area Survey of Trauma. Am J Psychiatry 1999; 156: 902-7.

26 Krug EG, Sharma GK, Lozano R The global burden of injuries. Am J Public Health 2000; 90: 523-6.

27 Breslau, N. The epidemiology of trauma, PTSD, and other posttrauma disorders.Trauma Violence Abuse 2009; 10: 198-210.

28 Vries G, Olff $M$. The lifetime prevalence of traumatic events and posttraumatic stress disorder in the Netherlands. J Traum Stress 2009; 22: 259-67.

29 Ribeiro WS, Mari JDJ, Quintana MI, Dewey ME, Lacko SE, Vilete P, et al. The impact of epidemic violence on the prevalence of psychiatric disorders in Sao Paulo and Rio de Janeiro , Brazil. Plos One 2013; 8 : e63545

30 summerfield $D$. The invention of post-traumatic stress disorder and the social usefulness of a psychiatric category. BMJ 2001; 322: 95-8.

31 Ehlers A, Clark DM. A cognitive model of posttraumatic stress disorder. Behav Res Ther 2000; 38: 319-45.

32 Brewin CR, Andrews B, Valentine JD, Bromet E, Dekel R, Green B, et al. Meta-analysis of risk factors for posttraumatic stress disorder in trauma-exposed adults. 2000; 68: 748-66.

33 Pillen A. Masking Terror. How Women contain Violence in Southern Sri Lanka. Ethnography of Political Violence Series. Pennsylvania University Press, 2003

34 Jones $\mathrm{N}$, Seddon $\mathrm{R}$, Fear NT, McAllister $\mathrm{P}$, Wessely S, Greenberg N. Leadership, cohesion, morale, and the mental health of UK Armed Forces in Afghanistan Psychiatry 2012; 75: 49-59. 
35 Jones E, Vermaas RH, McCartney $\mathrm{H}$, Beech $\mathrm{C}$, Palmer I, Hyams $\mathrm{K}$, et al. Flashbacks and post-traumatic stress disorder: the genesis of a 20th-century diagnosis Br J Psychiatry 2003; 182: 158-63.

36 De Silva P. The tsunami and its aftermath in Sri Lanka: explorations of a Buddhist perspective. Int Rev Psychiatry 2006; 18: 281-7.

37 Rajkumar AP, Mohan TSP, Tharyan P. Lessons from the 2004 Asian tsunami: epidemiological and nosological debates in the diagnosis of post-traumatic stress disorder in non-Western post-disaster communities. Int J Soc Psychiatry 2013; 59: 123-9.

$38 \mathrm{Mol} \mathrm{SSL}$, Arntz A, Metsemakers JFM, Dinant GJ, Vilters-van Montfort PAP, Knottnerus JA. Symptoms of post-traumatic stress disorder after non-traumatic events: evidence from an open population study. Br J Psychiatry 2005; 186: 494-9.
39 Scott MJ, Stradling SG. Post-traumatic stress disorder without the trauma. Br J Clin Psychol 1994; 33: 71-4.

40 Hanwella R, De Silva V. Mental health of Special Forces personnel deployed in battle. Soc Psychiatry Psychiatr Epidemiol 2012; 47: 1343-51.

41 Hotopf M, Wessely S. Can epidemiology clear the fog of war? Lessons from the 1990-91 Gulf War. Int J Epidemiol 2005; 34: 791-800.

42 Knudsen AK, Hotopf M, Skogen JC, Overland S, Mykletun A. The health status of nonparticipants in a population-based health study: the Hordaland Health Study. Am J Epidemiol 2010; 172: 1306-14.

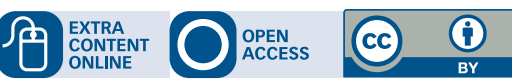

\section{reflection}

\section{The crooked wisdom of Francis Bacon's Essays}

\section{Alistair Stewart}

'Good advice for Satan's kingdom' - this was William Blake's opinion of the Essays of Francis Bacon (1561-1626), a man of wealth and taste who was sometime Chancellor to King James I of England, and an intellectual godfather to the future Royal Society. In his essays, Bacon dealt with many things, including friendship, travel and gardens, but his focus was particularly on statecraft, and what would now be called 'man-management'.

In a concentrated style, he offers counsel to those in powerful positions:

'The vices of authority are chiefly four: delays, corruption, roughness and facility. For delays; give easy access; keep times appointed; go through with that which is in hand; and interlace not business but of necessity ... For roughness, it is a needless cause of discontent: severity breedeth fear, but roughness breedeth hate. Even reproofs from authority ought to be grave, and not taunting ...'

He describes how to get things done, in words which should resonate with any doctor who finds themselves sitting on a committee:

'There be three parts of business: the preparation, the debate or examination, and the perfection. Whereof, if you look for dispatch, let the middle only be the work of many, and the first and last the work of few.'

With respect to manipulation and control for political purposes, he is brutally frank:

'If you would work any man, you must either know his nature and fashions, and so lead him; or his ends, and so persuade him; or his weakness and disadvantages, and so awe him; or those that have interest in him, and so govern him.'

He offers examples of how to deceive and defraud which have a familiar ring:

'In things that a man would not be seen in himself, it is a point of cunning to borrow the name of the world; as to say, The world says, or, There is a speech abroad.'

At the same time he suggests how we can guard against those who seek to manipulate us:

'In dealing with cunning persons, we must ever consider their ends, to interpret their speeches; and it is good to say little to them, and that which they least look for.'

On one recent estimate, the leadership training industry is now worth $£ 30$ billion worldwide. Health service organisations have a huge appetite for its products, which contain a large amount of recycled and context-free platitudes. By contrast, whatever their moral status, Francis Bacon's observations from the chambers, passages and staircases of 17th-century London have a refreshing directness.

Leadership is always exercised for a particular purpose. The kind of leadership we need is determined by the direction in which we want to travel. Especially in a field as politically charged as the provision of healthcare, some awareness of the dark side of political manoeuvring is essential, just as it was to Bacon and his contemporaries. As he wrote elsewhere,

'It is not possible to join serpentine wisdom with columbine innocency, except men know exactly all the conditions of the serpent.' 